\title{
SISTEM PAKAR UJI KOMPETENSI BAGI SISWA BERKEBUTUHAN KHUSUS AUTIS DENGAN MENGGUNAKAN METODE SINGLE LINKAGE
}

\author{
Baginda Suryanto, Anton Setiawan Honggowibowo, Yuliani Indrianingsih \\ Jurusan Teknik Informatika \\ Sekolah Tinggi Teknologi Adisutjipto Yogyakarta \\ informatika@stta.ac.id
}

\begin{abstract}
Conventional knowledge test on the learning outcomes that have been given by previous teachers, often making bored students with autism. The results obtained are less accurate and require teachers to perform even the repetition of material grading explanations often not objective. Provision of additional material not often right on target and even students who need to get a repetition of material often do not get the repetition of material. Expert Systems Competency Test Program for Students with Special Needs Autism is designed with the needs of the school that is the subject of research and data collection. Cluster analysis works by grouping students by similarity score minimum euclidian distance of each data. This program tests every student and provide an explanation for the repetition of questions whose answers are not in accordance with the specified result.Program based on the use of Expert Systems Competency Test for Students with Special Needs Autism, the results obtained grouping students based on their level of intelligence that has been stored in the process of testing the competency test conducted by the students with autism. So that teachers can provide in the future teaching methods to suit the needs of students in order to enhance the level of intelligence of autistic students.
\end{abstract}

Keywords : expert system, competency test, single linkage method, autism.

\section{Pendahuluan}

Uji pengetahuan konvensional terhadap hasil pembelajaran yang telah diberikan oleh pengajar sebelumnya sering membuat bosan siswa autis. Hasil yang dicapai kurang akurat dan membutuhkan tenaga pengajar untuk melakukan pengulangan penjelasan materi. Nilai yang diberikan terkadang lebih cenderung ke arah subjektivitas bukan objektivitas. Selain itu dalam pengulangan materi yang diberikan oleh pengajar sering dianggap tidak tepat sasaran, siswa yang kurang pandai terkadang lolos dalam proses pengulangan materi.

\section{Metodologi}

Dijelaskan bahwa tidak mudah melakukan analisis cluster secara manual untuk jumlah objek yang sedikit apalagi untuk objek yang banyak sehingga diperlukan bantuan komputer. Algoritma 1 dapat dimodifikasi agar menjadi lebih efisien. Algoritma 2 lebih efisien daripada algoritma 1. Kutipan ini diambil dari (Rito Goejantoro, 2009) Jurnal Informatika Mulawarman Volume 4, Nomor 3, 2009 dengan judul Algoritma Pengklusteran Pautan Tunggal. 


\subsection{Pautan Tunggal (Single Linkage)}

Pautan Tunggal (Single linkage) adalah suatu proses pengklasteran yang didasarkan pada jarak terdekat objek data. Apabila terdapat dua objek data terpisah oleh jarak yang pendek, maka kedua objek data tersebut akan digabung menjadi satu cluster dan demikian seterusnya.

Berikut ini langkah-langkah yang digunakan dalam metode pautan tunggal:

1. Standarisasi data yang akan dikelompokkan, tujuan dilakukan standarisasi data adalah agar data mempunyai skala yang sama, sehingga pengelompokan akan menjadi lebih stabil. Adapun rumus untuk standarisasi adalah sebagai berikut:

$\overline{\mathrm{X}}=\frac{\sum_{i=1}^{n} X i}{n}$

$\operatorname{std}(X)=\sqrt{\frac{\sum_{i=1}^{n} X i}{n-1}}$

$Z i=\frac{X i-\bar{X}}{\operatorname{std}(X)}$

Keterangan:

$\mathrm{Xi} \quad=$ data $X \mathrm{ke}-\mathrm{i}$

$X \quad=$ rata-rata data $X$

$\mathrm{N} \quad=$ banyak data $X$

Std $(X)=$ standar deviasi data $X$;

$\mathrm{Zi} \quad=$ data standar (skor standar) $X$ ke- $\mathrm{i}$

2. Menentukan ukuran kemiripan atau ketidakmiripan antara data dengan data yang lain menggunakan metode jarak Euclidean, rumus yang digunakan adalah sebagai berikut:

$\mathrm{d}(\mathrm{x}, \mathrm{y})=\sqrt{\left(X_{1}-Y_{1}\right)^{2}+\left(X_{2}-Y_{2}\right)^{2}+\cdots+\left(X_{n}-Y_{n}\right)^{2}}$

3. Setelah tahap di atas selesai dilakukan, maka langkah selanjutnya adalah melakukan pengelompokan dengan metode Single Linkage, dengan langkahlangkah sebagai berikut:

a. Mulai dengan $\mathrm{N}$ kelompok masing-masing beranggotakan 1 dan diketahui matriks jarak D.

b. Cari jarak terkecil, misalkan kelompok $U$ dan $V$ mempunyai jarak $\mathrm{d}_{u v}$.

c. Gabungkan kelompok U dan V, dan beri label uv, dan menambahkan satu baris dan kolom untuk kelompok uv.

d. Menentukan kembali matriks jarak untuk uv, dengan membandingkan nilai terkecil dalam kolom yang sudah dihapus.

e. Ulangi tahapan 2 dan 3 sebanyak N-1 kali (sampai tersisa hanya 2 kelompok). 


\subsection{Diagram Konteks}

Diagram konteks pada Gambar 1 adalah diagram level tertinggi dari DAD (Diagram Alir Data) yang menggambarkan hubungan sistem dengan lingkungan luarnya. Pada Sistem Pakar Uji Kompetensi Bagi Siswa Berkebutuhan Khusus Autisini, sistem berhubungan dengan siswa, guru dan orangtua.

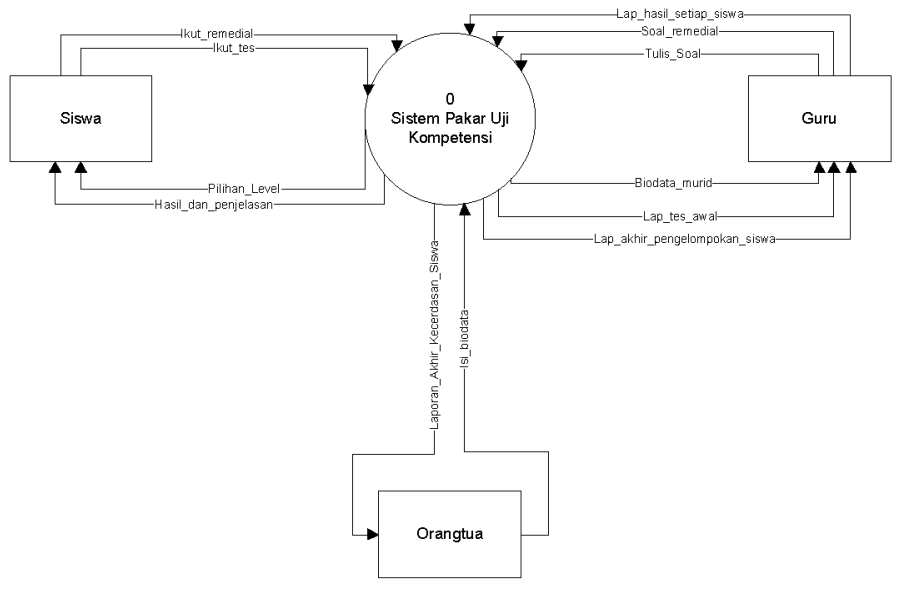

Gambar 1. Diagram Konteks

\subsection{Flow Chart}

Flow Chart merupakan cara untuk menggambarkan alur sistem program. Perintah yang dituliskan dalam simbol, memperlihatkan aliran proses dari sebuah bagian program ke bagian program lainnya.

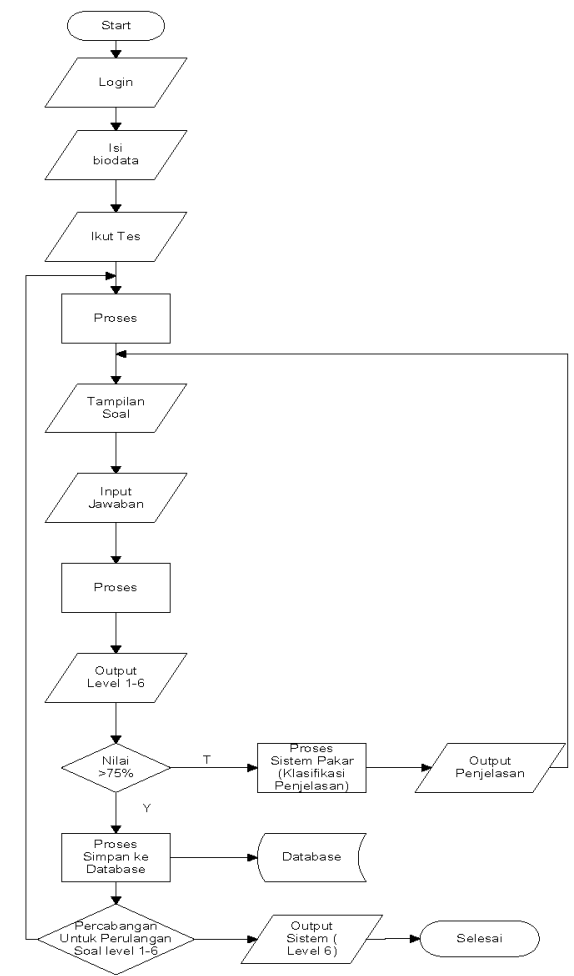

Gambar 2. Flow Chart Aplikasi 


\subsection{Entity Relationship Diagram (ERD)}

ERD adalah suatu pemodelan dari basis data relasional yang didasarkan atas persepsi di dalam dunia nyata, yang terdiri dari sekumpulan objek yang saling berhubungan antara satu dengan yang lainnya.

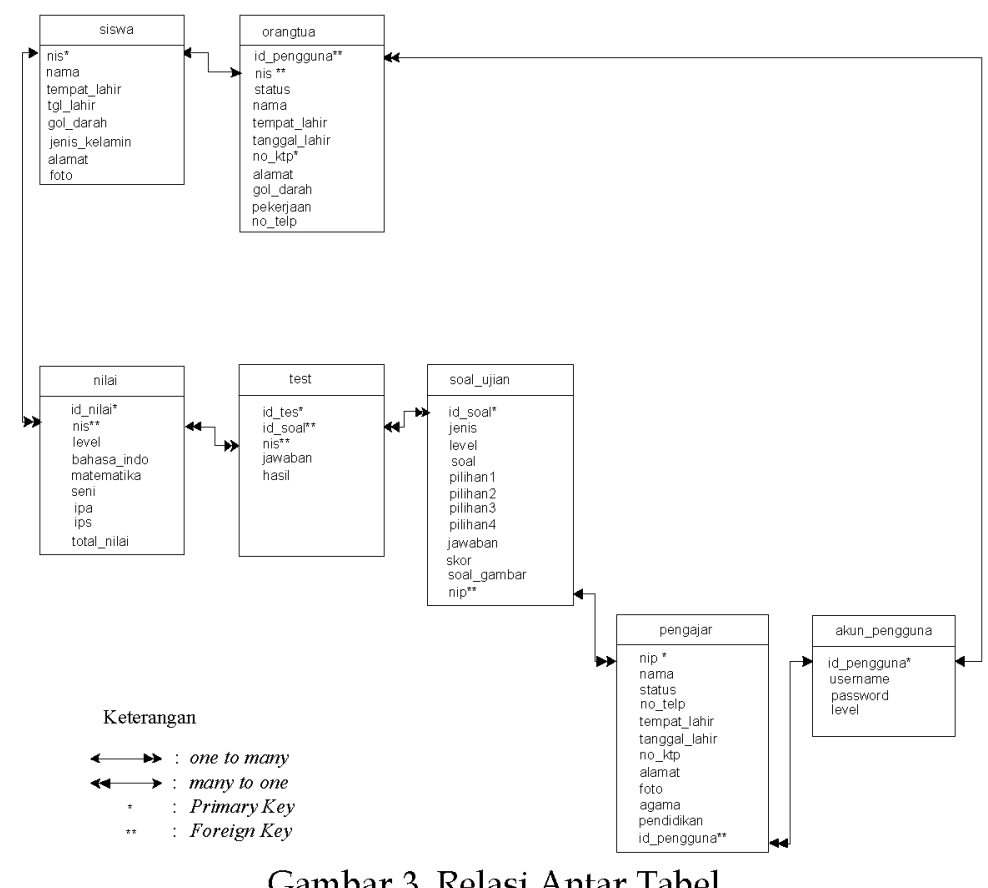

\section{Hasil dan Pembahasan}

Pada aplikasi ini, metode Analisis Cluster teraplikasikan pada form report kelas secara keseluruhan. Pada form tersebut, memberikan analisis nilai-nilai siswa yang telah tersimpan dalam database. Analisis tersebut memberikan hasil kelompok siswa yang termasuk ke dalam tingkat kecerdasan rendah hingga tingkat kecerdasan tinggi. Metode ini mempermudah pengajar untuk memberikan pelatihan ataupun pengajaran yang dibutuhkan oleh siswa berkebutuhan khusus tersebut sesuai dengan tingkat kecerdasan yang siswa tersebut miliki.

\subsection{Proses Perhitungan Manual}

Proses penghitungan analisis cluster diawali dengan pengambilan data (nilai siswa) dengan cara mengikuti dan menjawab pertanyaan-pertanyaan yang disuguhkan dalam tes uji kompetensi. Setiap siswa yang telah mengikuti tes uji kompetensi tersebut akan mendapatkan nilai yang tersimpan dalam database, sehingga dapat diperoleh data siswa pada tingkatan tes pertama. Siswa objek atau siswa (nama orang) dimisalkan dengan angka (1,2,3,4 dan seterusnya), dan syarat atau variabel dimisalkan dengan huruf (V1, V2, V3, V4 dan V5) agar mempermudah dalam perhitungan. Data yang ada di dalam Tabel Nilai Siswa, kemudian dihitung dengan menggunakan metode single linkage clustering. Langkah-langkahnya adalah sebagai berikut:

Menstandarisari data-data yang telah terkumpul dalam tabel, dengan menggunakan rumus-rumus yang telah tersedia 
1. Mencari rata-rata data dari setiap variable Rata-rata V1 $(\overline{X 1})$

$$
\begin{aligned}
& \overline{X 1}=\frac{V 1,1+V 1,2+V 1,3+V 1,4+V 1,5+V 1,6+V 1,7+\cdots+V 1,29+V 1,30}{30} \\
& \overline{X 1}=\frac{100+57+29+46+72+43+82+\cdots+100+100}{30} \\
& \overline{X 1}=\frac{1506}{30}=50,2
\end{aligned}
$$

Sehingga diperoleh data pada Tabel 1 Rata-Rata.

Tabel 1 Rata-Rata
\begin{tabular}{|l|l|}
\hline v1 & 50,2 \\
\hline v2 & 48,77 \\
\hline v3 & 50,23 \\
\hline v4 & 39,17 \\
\hline v5 & 42,77 \\
\hline
\end{tabular}

2. Mencari standar deviasi data dari setiap variabel

$$
\begin{aligned}
& s t d V 1=\sqrt{(1-\overline{X 1})^{2}+(2-\overline{X 1})^{2}+(3-\overline{X 1})^{2}+\cdots+(30-\overline{X 1})^{2}} \\
& s t d V 1=\sqrt{(100-50,2)^{2}+(57-50,2)^{2}+(29-50,2)^{2}+\cdots+(30-50,2)^{2}} \\
& \operatorname{std} V 1=152,45
\end{aligned}
$$

Perhitungan standar deviasi dilakukan pada setiap variable (V1 sampai V5). Hasil dari perhitungan standar deviasi ini, dimasukkan dalam Tabel 2 Standar Deviasi.

Tabel 2 Standar Deviasi

\begin{tabular}{|l|l|}
\hline std V1 & 152,45 \\
\hline std V2 & 148,28 \\
\hline std V3 & 176,51 \\
\hline std V4 & 176,77 \\
\hline std V5 & 170,48 \\
\hline
\end{tabular}

3. Mencari skor standar/zero dari masing-masing objek pada setiap variabel. Skor standar untuk variabel 1 pada objek 1,2,3

$$
\begin{aligned}
& Z(v 1,1)=\frac{v 1,1-\overline{X 1}}{s t d v 1}=\frac{100-50,2}{152,45}=0,327 \\
& Z(v 1,2)=\frac{v 1,2-\overline{X 1}}{s t d v 1}=\frac{57-50,2}{152,45}=0,045
\end{aligned}
$$


$Z(v 1,3)=\frac{v 1,3-\overline{X 1}}{s t d v 1}=\frac{29-50,2}{152,45}=-0,139$

Perhitungan standar deviasi dilakukan pada setiap objek (1-30) dengan setiap variabel 1 hingga variabel 5 . Hasil dari perhitungan standar deviasi ini, dimasukkan dalam Tabel 3 Z-Skor.

Tabel 3 Z-Skor

\begin{tabular}{|r|r|r|r|r|}
\hline$z(v 1 n)$ & $z(v 2 n)$ & $z(v 3 n)$ & $z(v 4 n)$ & $z(v 5 n)$ \\
\hline 0,327 & 0,177 & 0,282 & 0,344 & 0,336 \\
\hline 0,045 & 0,163 & 0,140 & 0,044 & 0,189 \\
\hline$-0,139$ & $-0,005$ & 0,129 & 0,078 & 0,066 \\
\hline$-0,028$ & 0,157 & $-0,285$ & $-0,222$ & 0,037 \\
\hline 0,143 & 0,163 & $-0,013$ & 0,197 & 0,048 \\
\hline$-0,047$ & 0,022 & 0,123 & $-0,069$ & $-0,104$ \\
\hline 0,209 & $-0,012$ & $-0,126$ & $-0,074$ & $-0,104$ \\
\hline$-0,021$ & $-0,140$ & 0,010 & $-0,108$ & 0,060 \\
\hline$-0,146$ & $-0,194$ & $-0,126$ & $-0,074$ & $-0,251$ \\
\hline 0,018 & $-0,194$ & 0,010 & 0,039 & 0,019 \\
\hline$-0,211$ & $-0,329$ & $-0,171$ & $-0,222$ & $-0,087$ \\
\hline$-0,028$ & 0,022 & 0,027 & 0,078 & $-0,087$ \\
\hline$-0,165$ & $-0,147$ & $-0,143$ & $-0,222$ & $-0,251$ \\
\hline 0,025 & 0,029 & 0,169 & $-0,069$ & $-0,128$ \\
\hline$-0,329$ & 0,157 & $-0,030$ & $-0,222$ & $-0,251$ \\
\hline$-0,028$ & $-0,194$ & $-0,126$ & 0,084 & 0,213 \\
\hline 0,045 & 0,042 & 0,123 & 0,197 & 0,213 \\
\hline$-0,165$ & $-0,329$ & $-0,285$ & $-0,222$ & $-0,251$ \\
\hline 0,163 & 0,163 & $-0,132$ & 0,084 & 0,066 \\
\hline$-0,329$ & $-0,147$ & $-0,285$ & $-0,222$ & $-0,251$ \\
\hline 0,143 & $-0,005$ & 0,169 & 0,078 & 0,066 \\
\hline$-0,047$ & 0,029 & 0,140 & 0,197 & 0,189 \\
\hline 0,209 & 0,157 & 0,010 & $-0,108$ & 0,060 \\
\hline$-0,329$ & $-0,329$ & 0,282 & $-0,222$ & $-0,251$ \\
\hline 0,018 & 0,029 & $-0,285$ & $-0,108$ & 0,066 \\
\hline 0,136 & 0,042 & 0,129 & 0,084 & $-0,098$ \\
\hline 0,045 & 0,177 & $-0,018$ & 0,191 & 0,189 \\
\hline$-0,165$ & $-0,194$ & $-0,285$ & $-0,222$ & $-0,251$ \\
\hline 0,327 & 0,346 & 0,282 & 0,344 & 0,336 \\
\hline 0,327 & 0,346 & 0,282 & 0,344 & 0,213 \\
\hline & & & & \\
\hline & & \\
\hline & & \\
\hline & & \\
\hline &
\end{tabular}

4. Menentukan ukuran kemiripan atau ketidakmiripan antar data dengan jarak euclidian.

$$
\mathrm{d}(\mathrm{x}, \mathrm{y})=\sqrt{\left(X_{1}-Y_{1}\right)^{2}+\left(X_{2}-Y_{2}\right)^{2}+\cdots+\left(X_{n}-Y_{n}\right)^{2}}
$$

Mencari Jarak 1-2 (Objek 1 dan Objek 2)

$$
\mathrm{d}(1,2)=\sqrt{(0,327-0,045)^{2}+(0,177-0,163)^{2}+\cdots+(0,336-0,189)^{2}}
$$


$d(1,2)=0,4596$

$\mathrm{d}(1,3)=\sqrt{(0,327-(-0,139))^{2}+\cdots+(0,344-0,078)^{2}+(0,336-0,066)^{2}}$ $d(1,3)=0,6457$

Perhitungan jarak euclidian dilakukan terhadap seluruh objek yang tersisa, dengan rumus (n , n-1), dimana n sebagai objek yang akan dicari jarak euclidian, sehingga didapatkan data Jarak Euclidian.

5. Melakukan pengelompokkan objek berdasarkan metode analisis cluster menggunakan euclidian single lingkage clustering.

Setelah didapat data berdasarkan penghitungan jarak euclidian maka terbentuklah sebuah matriks awal yang akan dijadikan sebagai dasar permulaan pengelompokan objek. Gambar 4 merupakan gambar matriks pertama yang dihasilkan dalam pengelompokan objek tersebut.

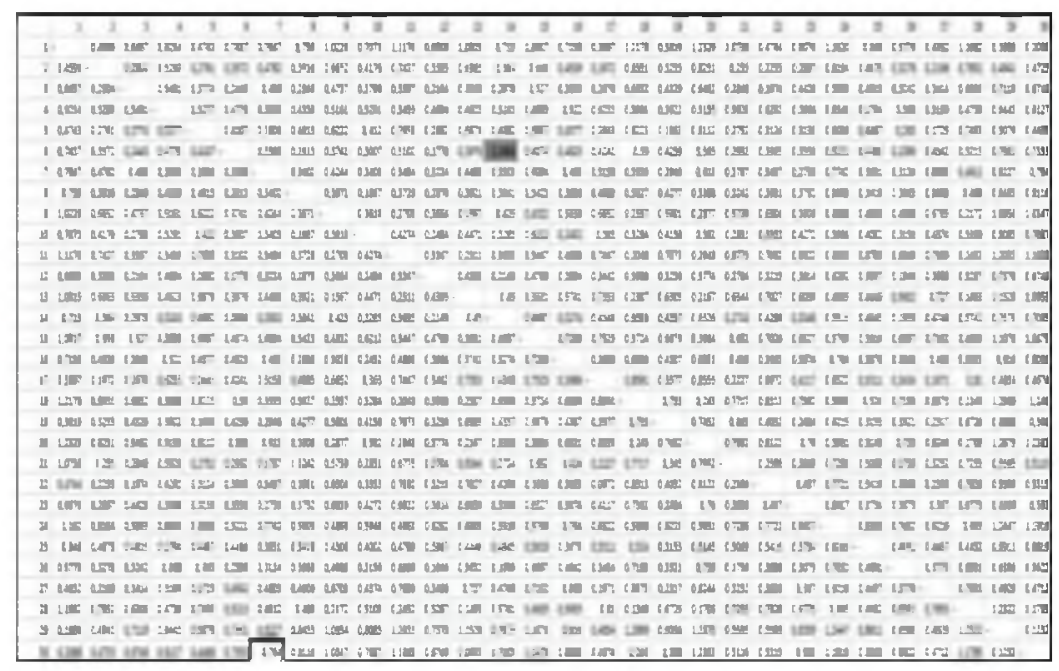

Gambar 4. Matriks Pertama

Dari data-data matrik jarak yang sudah diperoleh, dilakukan algoritma pengelompokan Euclidean single linkage, dengan langkah-langkah seperti diatas, yaitu 1. Mencari matriks jarak n-1 kali $(30-1=29)$

a. Mencari nilai terkecil dari matriks jarak. Berdasarkan matriks jarak di atas, nilai terkecilnya adalah 0,0886 . 


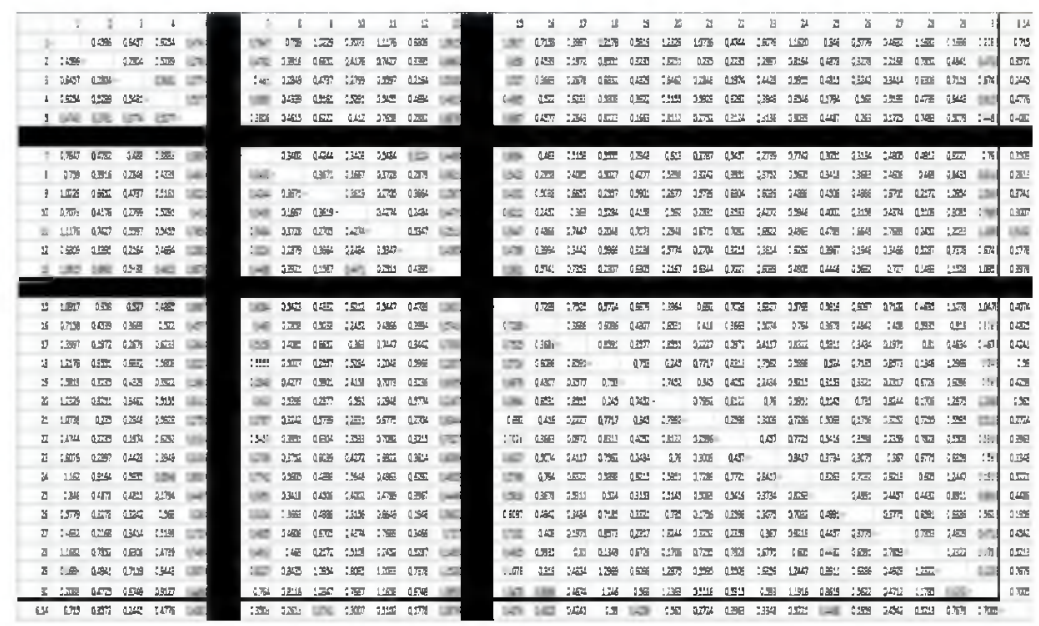

Gambar 5. Matriks Kedua

b. Menghapus kolom dan baris pembentuk nilai terkecil yaitu 6 dan 14, dan membentuk kolom dan baris baru yang objeknya merupakan gabungan dari objek yang dihapus, yaitu 6 dan 14. Kolom dan baris baru tersebut disebut 6,14 .

c. Menentukan nilai untuk kelompok AJ, dengan cara membandingkan nilai terkecil dari setiap kolom dan baris dari objek 6 dan 14. Proses ini menghasilkan matriks baru seperti pada Gambar 5 .

d. Memulai langkah a,b dan c sebanyak n-1 kali ( hingga tersisa hanya dua objek)

Hasil matriks ke 28 diperoleh hasil pengelompokkan siswa menjadi tiga kelompok yakni, kelompok pertama $(1,29,30)$, kelompok kedua $(15,4,25,7$, $23,3,2,17,22,27,5,19,21,26,12,6,14,16,8,10,11,9,13,18,20,28)$ dan kelompok ketiga (24). Hal ini disebabkan oleh perbedaan jarak euclidian yang besar dari ketiga kelompok. Kelompok objek yang memiliki kecerdasan yang tinggi berada pada kelompok pertama, kemudian kelompok kedua merupakan kumpulan objek yang memiliki kesamaan jarak euclidian atau dalam hal ini memiliki tingkat kecerdasan yang menengah ke bawah. Sedangkan kelompok tiga terjadi karena objek memiliki kesempurnaan nilai pada salah satu ketegori mata pelajaran meskipun pada kategori lain objek tersebut tidak memiliki nilai sama sekali. Apabila matriks ini diteruskan, maka akan terbentuk dua kelompok, yakni kelompok pertama $(15,4,25,7,23,3,2,1722,27,5,19,21,26,12,6,14,16,8$, $10,11,9,13,18,20,28,1,29,30)$ dan kelompok kedua (24) dengan nilai akhir sebesar 0,4898 . 


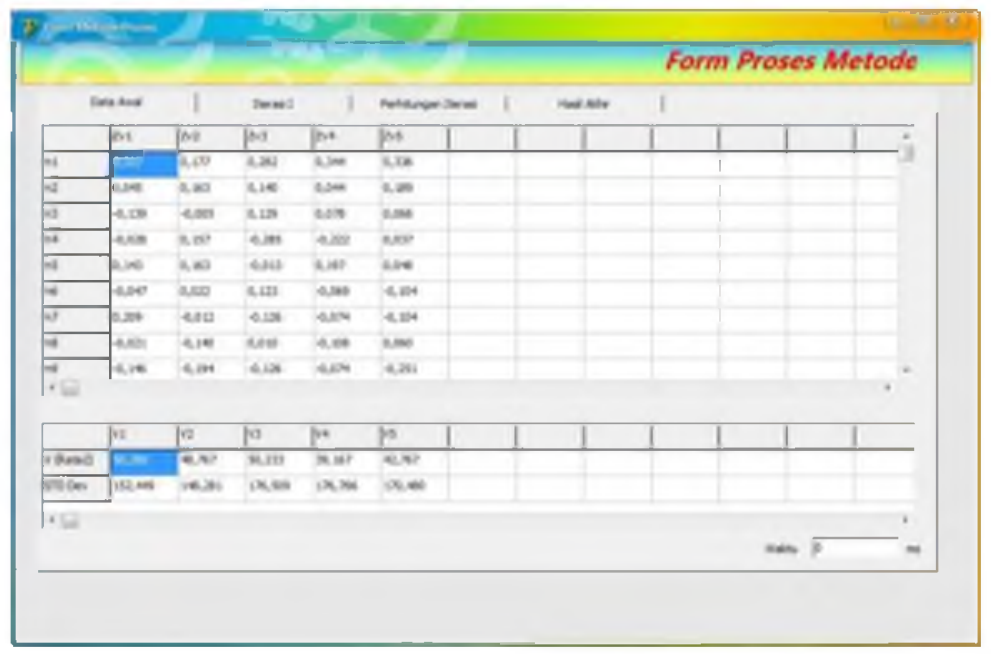

Gambar 6. Nilai Z Skor, Standar Deviasi dan V Rata-Rata

\subsection{Proses Perhitungan Menggunakan Aplikasi}

Pada tahap ini merupakan hasil perhitungan pengelompokkan objek berdasarkan data yang telah tersimpan dan memiliki nilai yang sama, maka diperoleh hasil seperti pada Gambar 6. Berdasarkan Gambar 6, dapat terlihat bahwa nilai yang didapatkan oleh perhitungan manual maupun perhitungan dengan menggunkan aplikasi tersebut bernilai sama. Hanya terdapat selisih yang diakibatkan pembulatan 3 angka di belakang koma yang terdapat pada hasil aplikasi. Namun, secara keseluruhan selisih tersebut tidak mengganggu hasil akhir yang diperoleh oleh aplikasi.

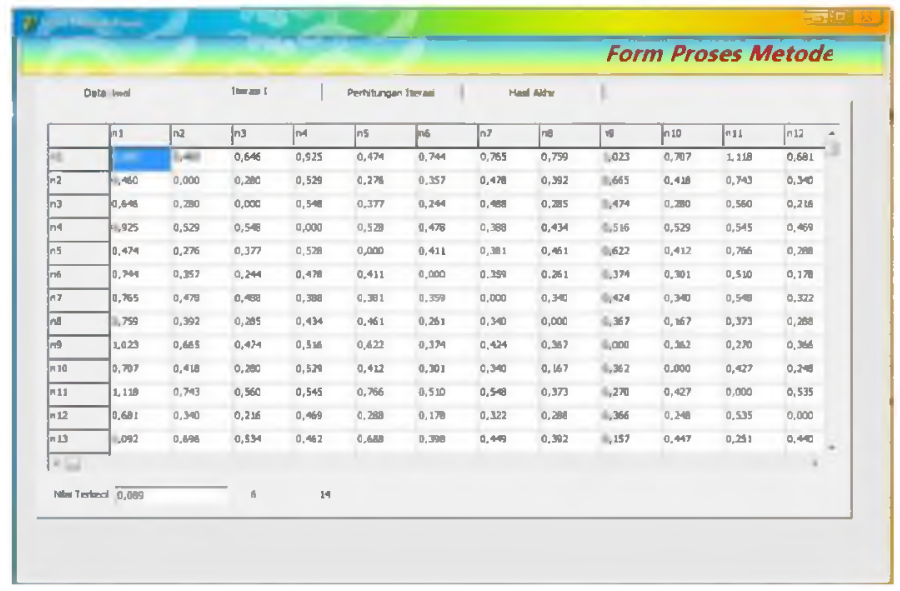

Gambar 7. Iterasi Pertama Menggunakan Aplikasi 


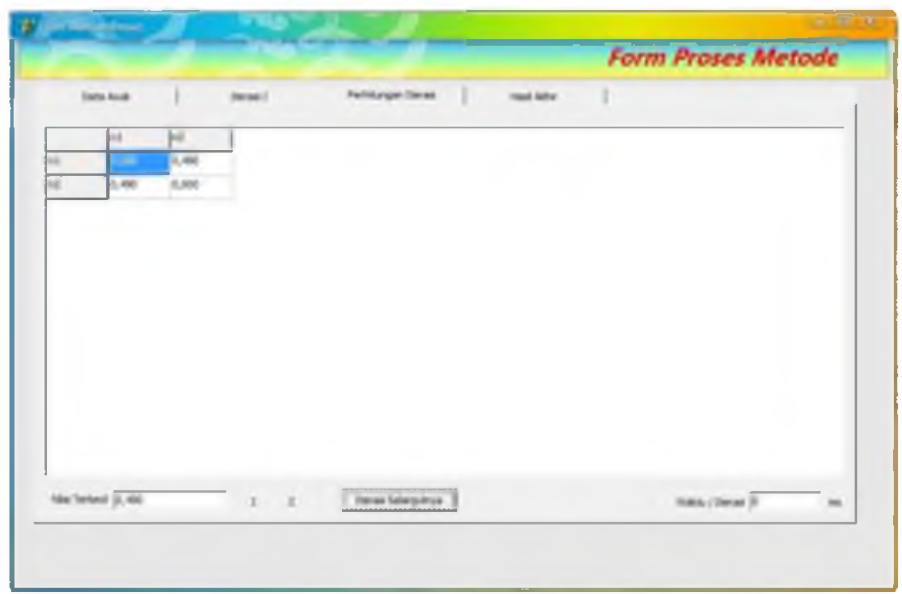

Gambar 8. Iterasi Tahap 29 Pada Aplikasi

Berdasarkan Gambar 7 dapat terlihat bahwa nilai iterasi yang didapatkan program aplikasi dengan yang didapatkan oleh perhitungan manual bernilai sama. Selisih yang muncul sama dengan permasalahan pada gambar sebelumnya, dikarenakan pembulatan tiga angka di belakang koma yang terdapat pada aplikasi tersebut.

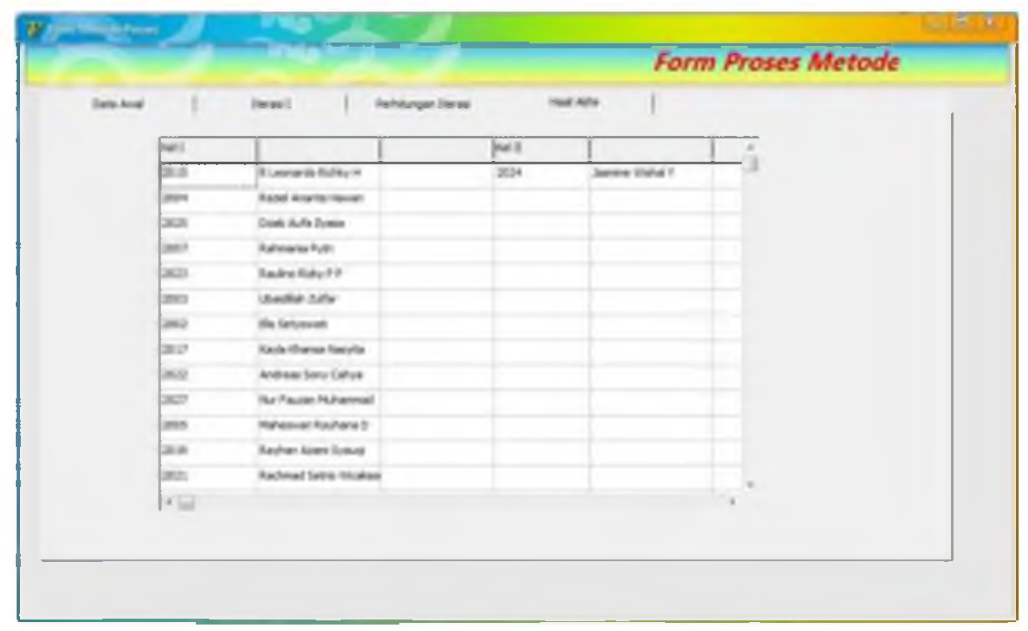

Gambar 9. Hasil Akhir Analisis Cluster

Pada Gambar 8 terlihat bahwa nilai akhir yang dihasilkan oleh aplikasi bernilai 0,490, sama dengan proses perhitungan manual. Sedangkan pada Gambar 9 juga terlihat hasil pengelompokan siswa yang sama dengan hasil yang diperoleh melalui perhitungan manual. Sehingga dapat ditarik kesimpulan bahwa data yang sama diimplementasikan dalam perhitungan manual maupun menggunakan aplikasi tersebut memiliki nilai akhir yang sama. Maka metode analisis cluster tersebut cocok dan dapat diterapkan pada Sistem Uji Kompetensi Bagi Siswa Berkebutuhan Khusus Autis tersebut.

\section{Kesimpulan dan Saran}

Kesimpulan yang diperoleh dari hasil analisa adalah sebagai berikut :

1. Aplikasi yang dirancang dalam tugas akhir ini, dapat digunakan untuk menguji materi hasil pembelajaran yang telah diberikan dalam proses belajar dan mengajar oleh pengajar sebelumnya. 
2. Sangat dibutuhkan sebuah aplikasi sistem pakar yang user friendly dimana aplikasi dapat digunakan dengan mudah oleh siswa yang memiliki keterbatasan bahasa dan dapat digunakan oleh pengajar (pakar).

3. Proses metode singlelinkage yang termasuk dalam analisis cluster yang terdapat dalam program ini bekerja untuk mengelompokan siswa berdasarkan tingkat kecerdasan, sehingga pengajar mendapatkan kemudahan untuk mempertimbangkan metode pengajaran ataupun tugas-tugas yang akan diberikan kepada para siswa guna untuk meningkatkan kemampuan yang para siswa miliki.

4. Metode single linkage cocok diterapkan pada sistem pakar dengan proses hasil perbandingan yang sama dengan aplikasi yang dirancang.

Pada proses pembuatan penelitian ini, aplikasi ini masih dapat dikembangkan antara lain:

1. Mata pelajaran yang disediakan lebih banyak dan tidak terbatas oleh syarat minimum ujian sekolah dasar saja.

2. Aplikasi ini dapat dikembangkan dengan metode lain yang membuat aplikasi ini dapat berjalan di berbagai tempat dan dapat digunakan oleh seluruh pengguna yang memerlukan aplikasi tersebut.

\section{Daftar Pustaka}

Husni.2004. Pemrograman Database dengan Delphi. Yogyakarta. Graha Ilmu.

Johnson, Richard A. Dan Dean W. Winchern. 2004. Applied Multivariate Statistical Analysis. Prentice Hall, Upper Saddler River. New Jersey.

Ladjamudin, Al-Bahra Bin.2005. Analisa dan Desain Sistem Informasi. Graha Ilmu. Yogyakarta.

Sutanto, Herry Tri. Cluster Analysis.Prosiding ISBN 978-979-16353-3-2. Seminar Nasional Matematika dan Pendidikan Matematika. UNY. Yogyakarta.

Turban, Efraim, dkk. 2005. Dicision Support Systems and Intelligent Systems-7th Ed Jilid 2( Sistem Pendukung Keputusan dan Sistem Cerdas). Andi Offset. Yogyakarta. 
Mukhamad Richo Mafazan, Sumarsono, Nurcahyani Dewi Retıowati 